\title{
Novel antimicrobial secondary metabolites from a Penicillium sp. isolated from Brazilian cerrado soil
}

\author{
Philippe Petit \\ Departamento de Química, ICEx \\ Universidade Federal de Minas Gerais \\ Belo Horizonte, MG, Brazil \\ Esther M. F. Lucas \\ Departamento de Química, ICEx \\ Universidade Federal de Minas Gerais and \\ Departamento de Química \\ Universidade Federal de Lavras \\ MG, Brazil \\ Lucas M. Abreu \\ Departamento de Química, ICEx \\ Universidade Federal de Minas Gerais \\ Belo Horizonte, MG, Brazi \\ Ludwig H. Pfenning \\ Departamento de Fitopatologia \\ Universidade Federal de Lavras \\ Lavras, MG, Brazil \\ Jacqueline A. Takahashi* \\ Departamento de Química, ICEx \\ Universidade Federal de Minas Gerais \\ Av. Antônio Carlos 6627, Pampulha \\ Belo Horizonte, MG, Brazil \\ E-mail: jat@qui.ufmg.br
}

Financial support: Conseil General de la Guadeloupe (grants to Dr. P. Petit), FAPEMIG (Brazil), CNPq (Brazil) and IFS (Sweden).

Keywords: antibacterial activity, cerrado, naphthalenoids, Penicillium, secondary metabolites.
Abbreviations: CYA: czapek yeast extract agar
DEPT: distortionless enhancement by polarization transfer DMF: dimethylformamide
EIMS: electron-ionization mass spectrometry
EtOAc: ethylacetate
G25N: 25\% glycerol nitrate agar
HMBC: heteronuclear multiple bond correlation
HMQC: heteronuclear multiple quantum coherence
MEA: malt extract agar
MIC: minimum inhibitory concentration
NMR: nuclear magnetic resonance
NOESY: nuclear overhauser and exchange spectroscopy
TLC: thin layer chromatography

The morphological features of a Penicillium, isolated from Brazilian cerrado soil, were characterized and showed to be distinctly different from all well-defined Penicillium species. Chemical and biological investigation on the ethyl acetate extract of this Penicillium isolate resulted in the isolation of three new naphthalenoids: a major metabolite, methyl 6-acetyl-4- methoxy-5, 7, 8-trihydroxynaphthalene-2-carboxylate and two minor ones, methyl 6-acetyl-4-methoxy-7,8dihydroxynaphthalene-2-carboxylate and methyl 6acetyl-4-methoxy-5, 8-dihydroxynaphthalene-2carboxylate. Their structures were determined based on their mono and bidimensional nuclear magnetic resonance data. Acetyl, allyl and methoxyl derivatives of

*Corresponding author 
the major metabolite were prepared in order to establish structure-activity relation. Antimicrobial activity of the major natural product and its semisynthetic derivatives was screened by macro dilution methodology and the corresponding minimum inhibitory concentrations were determined. Natural secondary metabolite methyl 6-acetyl-4-methoxy-5,7,8trihydroxynaphthalene-2-carboxylate, isolated in a very high yield (0.3175 mg. $\mathrm{L}^{-1}$ ) showed to be the most active compound, possessing expressive activity against Candida albicans (minimum inhibitory concentration (MIC) $32 \mu \mathrm{g} / \mathrm{mL}$ ), Listeria monocitogenes and Bacillus cereus (MIC $64 \mu \mathrm{g} / \mathrm{mL}$ for both).

Fungi play a major role in soil ecosystems along with bacteria, protists, small invertebrates and plants, through complex trophic interactions. Most soil fungi are regarded as saprobes, decomposing organic matter and contributing to nutrient cycling, while several species form mycorrhizal associations with plants or are plant pathogens (Pfenning and Abreu, 2006). Also recognized as prolific secondary metabolite producers, fungi have provided several bioactive compounds and chemical models currently used as pharmaceuticals, and soils are traditionally the main source of fungal genetic resources for bioprospection programs (Adrio and Demain, 2003). Despite that, the biodiversity and biotechnological potential of the soil mycobiota in many tropical regions is still poorly studied.

Cerrado is a savannah-like ecosystem that occupies around $20 \%$ of the Brazilian territory. It is characterized by a seasonal climate, old and weathered acidic soils with low nutrient and high aluminum content, and sparse vegetation. This quite hostile environment is thought to select species with adapted metabolism and good potential for delivering new bioactive metabolites. Indeed, the antimicrobial activity of several fungal species isolated from the cerrado soil towards pathogenic bacteria has been recently described by our group (Takahashi et al. 2008).

Penicillium is a large anamorphic (asexual state) ascomycetous fungal genus with widespread occurrence in most terrestrial environments. This genus comprises more than 200 described species and many are common soil inhabitants, as well as food borne contaminants or food ingredients used in the preparation of cheese and sausages (Pitt, 2000; Frisvad and Samson, 2004). Penicillium species produce a much diversified array of active secondary metabolites, including antibacterial (Rancic et al. 2006; Lucas et al. 2007), antifungal substances (Nicoletti et al. 2007), immunosuppressants, cholesterol-lowering agents (Kwon et al. 2002), and also potent mycotoxins (Frisvad and Samson, 2004). Thousands of Penicillium isolates have probably been screened in bioprospecting programs since the discovery of penicillin, and new bioactive metabolites continue to be discovered from these fungi nowadays (Larsen et al. 2007; Ge et al. 2008; Takahashi and Lucas, 2008), indicating their current importance as sources of high amounts of novel bioactive molecules to be used by pharmaceutical industry.

We have been screening a collection of filamentous fungi isolated from Serra do Cipó National Park soil, a preserved area of cerrado vegetation (Takahashi et al. 2008) for novel fungal natural products targeting at metabolites with biotechnological applications for the pharmaceutical industry. This fungal collection is mostly constituted by Penicillium species, such as Penicillium slerotiorum, Penicillium simplicissimum, Penicillium brasilianum, Penicillium janthinellum and Penicillium waksmanii and was fully tested for antibacterial activity (Takahashi et al. 2008). One of the most active extracts was obtained from a single Penicillium isolate with atypical morphological characteristics. From this isolate, three novel compounds
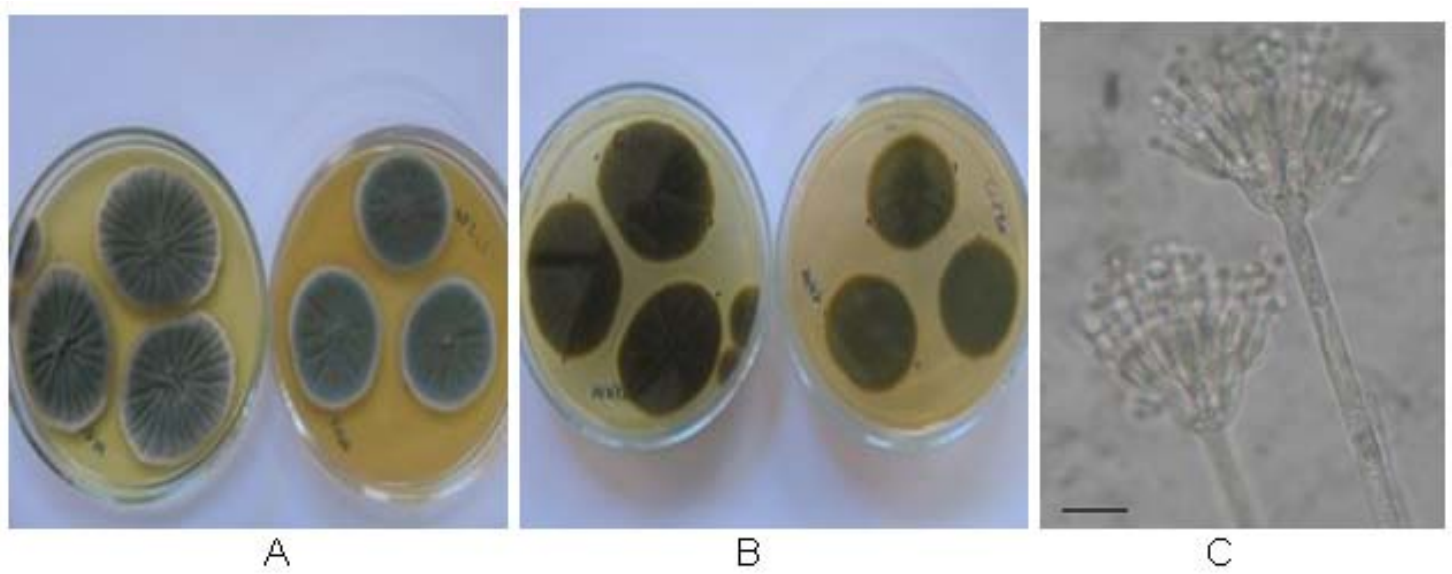

Figure 1. Colony appearance and micromorphology of Penicillium sp.

A - Colony appearance (obverse) after 7 days at $25^{\circ} \mathrm{C}$ on CYA (left) and MEA (right);

$\mathrm{B}$ - Colony appearance (reverse) after 7 days at $25^{\circ} \mathrm{C}$ on CYA (left) and MEA (right);

C - Conidiophores (original magnification $1000 \mathrm{X}$ ). Bar, $10 \mu \mathrm{m}$. 
Table 1. NMR spectroscopic data ( $\delta$ from TMS, multiplicity) for compounds 1,2 and 3.

\begin{tabular}{|c|c|c|c|c|c|c|}
\hline \multirow[b]{2}{*}{ Position } & \multicolumn{2}{|c|}{$\begin{array}{c}1 \\
\left(\mathrm{CDCl}_{3} / 0.1 \% \mathrm{DMSO}-\mathrm{d}_{6}\right)\end{array}$} & \multicolumn{2}{|c|}{$\stackrel{2}{2}$} & \multicolumn{2}{|c|}{$\begin{array}{c}3 \\
\left(D^{3} \mathrm{SO}-\mathrm{d}_{6}\right)\end{array}$} \\
\hline & $\delta_{H}$ & $\delta_{C}$ & $\delta_{H}$ & $\delta_{c}$ & $\delta_{\mathrm{H}}$ & $\delta_{c}$ \\
\hline 1 & $\begin{array}{l}7.07, d \\
(J=2 H z)\end{array}$ & 108.56 & $\begin{array}{c}6.95, \mathrm{~d} \\
(J=2.1 \mathrm{~Hz})\end{array}$ & 109.02 & $\begin{array}{c}6.97, \mathrm{~d} \\
(J=2.1 \mathrm{~Hz})\end{array}$ & 109.09 \\
\hline 2 & & 128.69 & & 130.10 & & 130.10 \\
\hline 3 & $\begin{array}{c}6.65, d \\
(J=2 H z)\end{array}$ & 103.65 & $\begin{array}{c}6.65, \mathrm{~d} \\
(\mathrm{~J}=2.1 \mathrm{~Hz})\end{array}$ & 104.46 & $\begin{array}{c}6.67, \mathrm{~d} \\
(J=2.1 \mathrm{~Hz})\end{array}$ & 104.46 \\
\hline 4 & & 157.16 & & 159.37 & & 158.86 \\
\hline 5 & & 158.86 & $6.12, \mathrm{~s}$ & 108.95 & & 149.41 \\
\hline 6 & & 112.94 & & 112.80 & & 112.80 \\
\hline 7 & & 142.05 & & 149.41 & $6.23, \mathrm{~s}$ & 109.78 \\
\hline 8 & & 155.08 & & 160.70 & & 160.07 \\
\hline 9 & & 110.67 & & 111.00 & & 112.00 \\
\hline 10 & & 125.58 & & 127.85 & & 127.85 \\
\hline $\mathrm{CH}_{3}-6$ & $2.64, \mathrm{~s}$ & 18.96 & $2.19, \mathrm{~s}$ & 22.18 & $2.29, \mathrm{~s}$ & 21.18 \\
\hline $\mathrm{OCH}_{3}-2$ & $3.72, \mathrm{~s}$ & 52.23 & $3.70, \mathrm{~s}$ & 52.62 & $3.70, \mathrm{~s}$ & 52.71 \\
\hline $\mathrm{OCH}_{3}-4$ & $3.70, \mathrm{~s}$ & 56.13 & $3.66, \mathrm{~s}$ & 56.70 & $3.68, \mathrm{~s}$ & 56.70 \\
\hline $\mathrm{CO}-2$ & & 166.17 & & 163.44 & & 168.06 \\
\hline CO-6 & & 200.31 & & 202.31 & & 202.31 \\
\hline $\mathrm{OH}-5,7,8$ & $\begin{array}{l}10.8(2 \mathrm{H}) \text { and } \\
9.51(1 \mathrm{H}), \text { br s }\end{array}$ & & & & & \\
\hline
\end{tabular}

$\mathrm{s}=$ singlet; $\mathrm{d}=$ doublet; $\mathrm{br} \mathrm{s}=$ broad singlet

(1-3) were isolated, identified and tested for antibacterial and antifungal activities, along with three semi-synthetic derivatives prepared from compound $\mathbf{1}$.

\section{MATERIALS AND METHODS}

\section{General experimental procedures}

Column chromatography was performed on silica gel (Merck, Darmstadt, Germany) (230-400 mesh). Thin layer chromatography (TLC) was performed on commercial TLC plates (pre-coated Kiesegel $60 \mathrm{~F}_{254}$ TLC, 20 x $20 \mathrm{~mm}$, thickness $0.25 \mathrm{~mm}$, Merck). Culture medium was prepared with glucose (Labsynth, Brazil), peptone (Isofar 2115, Brazil) and yeast extracts (Biobras, Brazil). Solvents used for chromatography (column and thin layer) were purchased from Grupo Química (São Paulo, Brazil). Deuterated solvents, reagents and dimethylformamide (DMF) were purchased from Aldrich Chemical Co. (Milwaukee, WI). Chloramphenicol and miconazole were purchased from Sigma Chemical Co. (St. Louis, MO). Infrared spectra were recorded on a Perkin Elmer 283b spectrometer. The samples were analyzed as $\mathrm{KBr}$ pellets. Electron-ionization mass spectrometry (EIMS) data were recorded on a Kratos concept II $\mathrm{H}$ mass spectrometer. ${ }^{1} \mathrm{H}$ 
nuclear magnetic resonance (NMR) and ${ }^{13} \mathrm{C}$ NMR spectra were obtained on Bruker model DRX 400 avance with standard pulse sequences operating at $400 \mathrm{MHz}$ for ${ }^{1} \mathrm{H}$ NMR and $100 \mathrm{MHz}$ for ${ }^{13} \mathrm{C}$ NMR.

\section{Isolation and characterization of the fungal isolate}

As part of a program aiming at the identification of antibiotic producing fungi, around 200 fungal isolates were recovered from 15 soil samples randomly collected from an area of native cerrado (Brazilian savannah) in the Serra do Cipó National Park, Minas Gerais State of Brazil. The fungi were isolated by soil dilution plate method and preserved at $4^{\circ} \mathrm{C}$ for further characterization (Takahashi et al. 2008). Among several Penicillium isolates recovered, one exhibited distinct cultural characteristics and was investigated in more detail.

Using the media and growth conditions specified by Pitt (2000), a wide range of morphological features of the Penicillium isolate were examined on Czapek yeast extract agar (CYA) at 25 and $37^{\circ} \mathrm{C}$; malt extract agar (MEA) at $25^{\circ} \mathrm{C}$; and $25 \%$ glycerol nitrate agar $(\mathrm{G} 25 \mathrm{~N})$ at $25^{\circ} \mathrm{C}$ incubated for 7 days in darkness. Microscopic preparations made from colonies cultivated on MEA and mounted in glycerin were used for evaluation of micromorphological traits of conidiophores and conidia. Light micrographs were taken at $1000 \mathrm{X}$ magnification in an Olympus CX40RF100 light microscope coupled to a Canon A620 digital camera. The cultural and morphological characteristics of the isolate were compared with species descriptions contained in the Penicillium manuals (Pitt, 1979; Pitt, 2000).

\section{Culturing of Penicillium sp., extraction and isolation of metabolites}

Spores of Penicillium sp. were inoculated in a medium prepared in distilled water containing glucose $(20 \mathrm{~g} / \mathrm{L})$, peptone $(10 \mathrm{~g} / \mathrm{L})$ and yeast extract $(5 \mathrm{~g} / \mathrm{L})$. The fungal culture (5 L) was incubated without agitation for 2 weeks at $25^{\circ} \mathrm{C}$. Once the incubation period was complete, mycelia was filtered off, soaked on ethylacetate (EtOAc) for $24 \mathrm{hrs}$ and filtered, resulting in an organic layer. The aqueous medium was submitted to a liquid-liquid extraction with EtOAc. Both EtOAc extracts were combined and concentrated under reduced pressure to yield $3.5 \mathrm{~g}$ of a brown solid. Mycelia and culture medium were also extracted with butanol $(\mathrm{BuOH})$ following the same procedure adopted for the EtOAc extract. Both extracts were tested for antimicrobial activity using the disc diffusion assay and only the EtOAc showed encouraging bioactivity. Therefore, only this extract was further investigated.

An aliquot of $2.8 \mathrm{~g}$ was taken from the EtOAc extract and subjected to silica gel column chromatography. Mixtures of hexane with increasing percentages of EtOAc were used to elute the compounds. The separation led to a number of fractions from where three main fractions were further studied. The first fraction (465 mg), eluted with 100\% hexane until hexane:EtOAc (8:2), was examined but proved to be mainly composed of a mixture of fatty acids and long chain alcohols. Fraction 2, eluted with hexane:EtOAc (1:1), gave compound 1 (1.27 g) after recristallization from hexane:acetone (1:1). Fraction 3, eluted with hexane:EtOAc (4:6), led to a mixture (26 mg) of compounds $\mathbf{1}, 2$ and 3 that was further chromatographed on preparative thin layer chromatography using hexane:EtOAc (1:1) as eluent, in order to remove compound $\mathbf{1}$. Compound $\mathbf{2}$ and $\mathbf{3}$ were obtained as a mixture $(4.8 \mathrm{mg})$, from which compound 2 was isolated by preparative thin layer chromatography in hexane:EtOAc (4:6).

Compound 1. [mp $215-217^{\circ} \mathrm{C}$; IR (KBr) $\lambda_{\max } 3443$, 3398, 1716, 1613, $1592 \mathrm{~cm}^{-1}$, EIMS m/z $159\left(\mathrm{C}_{6} \mathrm{H}_{7} \mathrm{O}_{5}\right)(100), 129$ (50), 101 (28), 143 (25), 201(15), 185 (13), 217 (10)], 2 and 3: ${ }^{1} \mathrm{H}$ and ${ }^{13} \mathrm{C}$ NMR data (Table 1 ).

Compound 4. (Acetylation procedure): To a solution of naphthotriol $1(0.05 \mathrm{mmol}, 15 \mathrm{mg})$ in pyridine $(1.0 \mathrm{~mL}) 1$ $\mathrm{mL}$ of acetic anhydride was added and the reaction mixture was left at room temperature for 48 hrs. After usual work up, the triacetate was obtained as yellow needles (acetone), mp $147-150^{\circ} \mathrm{C}$; IR (KBr) $\lambda_{\max } 3551,3478,3413,3236$, 1783, 1730, 1680, 1637 and $1617 \mathrm{~cm}^{-1} .{ }^{1} \mathrm{H}$ NMR, $\left(\mathrm{CDCl}_{3}\right.$, $400 \mathrm{MHz}) \delta: 7.25$ (d, $1 \mathrm{H}, J=1.8 \mathrm{~Hz}) \mathrm{H}-1 ; 6.82(\mathrm{~d}, 1 \mathrm{H}$, $J=1.8 \mathrm{~Hz}) \mathrm{H}-3$; 3.71 (s, 3H) $\mathrm{CH}_{3}-2,3.68$ (s, 3H) $\mathrm{CH}_{3}-4$, 2.57 (s, 3H) $\mathrm{CH}_{3}-6$; 2.32, 2.06 and 2.04 (s, 3H each) $\mathrm{CH}_{3}-$ 5, 7, 8. ${ }^{13} \mathrm{C} \mathrm{NMR}\left(\mathrm{CDCl}_{3}, 100 \mathrm{MHz}\right) \delta: 115.2$ (C-1); 131.4 (C-2); 109.3 (C-3); 158.1 (C-4); 152.4 (C-5); 127.5 (C-6); 140.0 (C-7); 145.3 (C-8); 125.2 (C-9); 129.2 (C-10); 52.8 $\left(\mathrm{CH}_{3}-2\right)$; $56.4\left(\mathrm{CH}_{3}-4\right) ; 29.7\left(\mathrm{CH}_{3}-6\right) ; 21.0,19.0,20.1$ $\left(\mathrm{CH}_{3}-5,7,8\right.$, respectively); 165.6, 167.6, 168.8, 167.5 (CO2, 5, 7, 8, respectively); 188.1 (CO-6).

Compound 5. (Allylation procedure): A solution of naphthotriol 1 (0.05 mmol, $15 \mathrm{mg}$ ), anhydrous $\mathrm{NaHCO}_{3}$ (15 mmol, $1.2 \mathrm{~g}$ ) and allyl bromide (15 mmol, $1.5 \mathrm{~mL})$ in acetone $(40 \mathrm{~mL})$ was refluxed for $24 \mathrm{hrs}$. Solvent was removed under vacuum and the residue was extracted from ethylacetate to yield the desired allyl ether as a gum.

${ }^{1} \mathrm{H} \mathrm{NMR}\left(\mathrm{CDCl}_{3}, 400 \mathrm{MHz}\right) \delta 6.69(\mathrm{~d}, 1 \mathrm{H}, J=2.3 \mathrm{~Hz}) \mathrm{H}-1$; 6.49 (d, 1H, $J=2.3 \mathrm{~Hz}$ ) H-3; 6.02 (m, 1H) H-7 (2'); 5.90 (m, 2H) H-5, 8 (2'); 5.41 (dd, $1 \mathrm{H}, J=17.21 \mathrm{~Hz}$ and $1.3 \mathrm{~Hz}) \mathrm{H}-7$ (3'anti); 5.32 (dd, $1 \mathrm{H}, J=10.4 \mathrm{~Hz}$ and $1.3 \mathrm{~Hz}$ ) H-7 (3'syn); 5.22 (dd, $2 \mathrm{H}, J=17.21 \mathrm{~Hz}$ and $1.4 \mathrm{~Hz}$ ) $\mathrm{H}-5,8$ (3'anti); 5.11 (dd, 2H, J=10.4 Hz and 1.2 Hz) H-5, 8 (3'syn); 4.6 (d, 2H, $J=5.6 \mathrm{~Hz}$ ) H-7(1'); 4.4 (d, 4H, $J=6 \mathrm{~Hz}$ ) H-5, 8 (1'), 3.81 (s, $3 \mathrm{H}) \mathrm{CH}_{3}-2,3.35(\mathrm{~s}, 3 \mathrm{H}) \mathrm{CH}_{3}-4,2.53(\mathrm{~s}, 3 \mathrm{H}) \mathrm{CH}_{3}-6$.

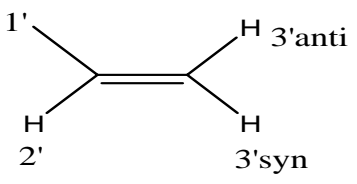

${ }^{13} \mathrm{C}$ NMR $\left(\mathrm{CDCl}_{3}, 100 \mathrm{MHz}\right) \delta 106.6$ (C-1); 131.1 (C-2); 101.4 (C-3); 160.7 (C-4); 162.3 (C-5); 133.3 (C-5,8 (2'); 


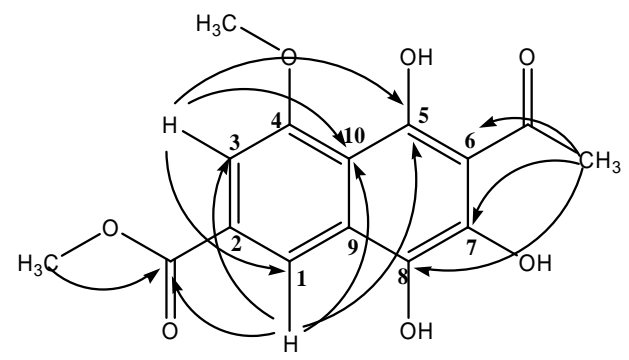

1

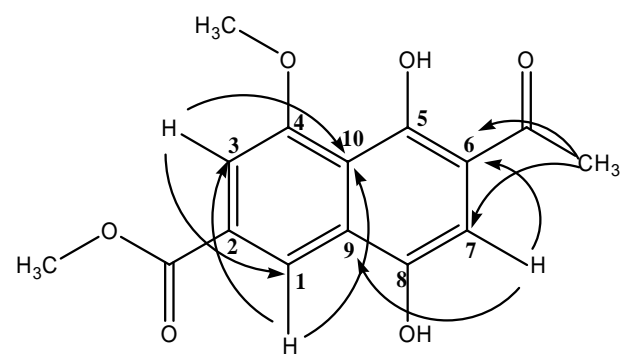

3

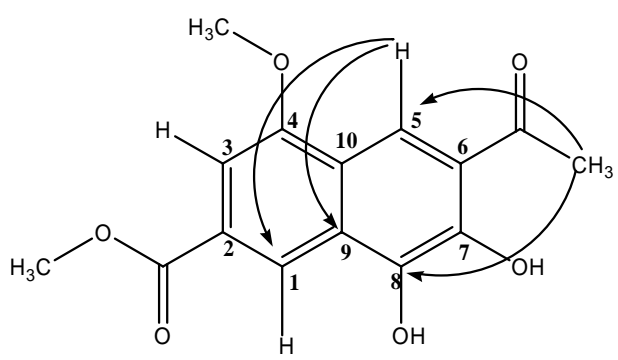

2<smiles></smiles>

$4 \mathrm{R}_{1}=\mathrm{R}_{2}=\mathrm{R}_{3}=\mathrm{Ac}$

$5 \mathrm{R}_{1}=\mathrm{R}_{2}=\mathrm{R}_{3}=$ Allyl

$6 \mathrm{R}_{1}=\mathrm{R}_{2}=\mathrm{OMe}, \mathrm{R}_{3}=\mathrm{H}$

Figure 2. Structure of compounds 1-6 and selected HMBC correlations indicated by arrows.

132.2 (C-7 (2’); 118.4 (C-7 (3’)); 117.8 (C-5,8 ( 3’)); 125.0 (C-6); 137.5 (C-7); 151.4 (C-8); 125.1 (C-9); 121.3 (C-10); 75.5 (C-5,8 (1'); 69.2 (C-7 (1')); $52.7\left(\mathrm{CH}_{3}-2\right)$; $56.2\left(\mathrm{CH}_{3^{-}}\right.$ 4); $18.5\left(\mathrm{CH}_{3}-6\right) ; 169.3$ (CO-2); 188.6 (CO-6).

Compound 6. (Methylation procedure): Sodium hydrogenocarbonate (5 mmol) and methyl iodide (5 mmol) were added sequentially to a solution of naphthotriol 1 (0.5 $\mathrm{mmol}$ ) in acetone. The resulting solution was stirred at room temperature for 48 hrs to yield the desired ether after usual work up. ${ }^{1} \mathrm{H} \mathrm{NMR}\left(\mathrm{CDCl}_{3}, 100 \mathrm{MHz}\right) \delta: 7.11(\mathrm{~d}, 1 \mathrm{H}$, $J=2.3 \mathrm{~Hz}, \mathrm{H}-1$ ); 6.67 (d, 1H, J=2.3 Hz, H-3); 3.89 (s, 3H, $\mathrm{CH}_{3}-2$ ), 3.76, 3.72, 3.25 (s, 3H each, $\mathrm{CH}_{3}-4,5$ and 7); 2.54 (s, 3H, $\left.\mathrm{CH}_{3}-6\right) .{ }^{13} \mathrm{C} \mathrm{NMR}\left(\mathrm{CDCl}_{3}, 100 \mathrm{MHz}\right) \delta$ : 105.4 (C1); 103.0 (C-3); 129.2 (C-3); 160.5 (C-4); 157.0 (C-5); 119.1 (C-6); 143.5 (C-7); 155.0 (C-8); 115.0 (C-9); 126.8 (C-10); $52.5\left(\mathrm{CH}_{3}-2\right)$; 60.6, 56.2, $55.8\left(\mathrm{CH}_{3}-4,5\right.$ and 8); $18.9\left(\mathrm{CH}_{3}-6\right) ; 166.0$ (CO-2); 199.9 (CO-6).

\section{Antimicrobial bioassays}

Test strains. The test strains, Listeria monocitogenes ATCC 19115, Streptococcus pyogenes ATCC 19615, Salmonella typhimurium ATCC 13311, Candida albicans ATCC 18804 and Bacillus cereus ATCC 11778 used for this study were obtained from American Type Culture Collection. The strain of Listeria sp. was provided by Instituto de Ciências Biológicas, UFMG, Brazil.
Bioassays. Disc diffusion test was carried out according to standard procedure (Lana et al. 2006). Minimum inhibitory concentration (MIC) was evaluated by the broth dilution test using standard inoculums of $10^{-5} \mathrm{CFU} \mathrm{mL}^{-1}$ (Rex et al. 2001). Serial dilutions of test compounds, previously dissolved in DMF, were prepared to final concentrations of $512,256,128,64,32,16,8,4,2$, and $1 \mu \mathrm{g}$ in $1 \mathrm{~mL}$ of brain hearth infusion (BHI) medium. To each tube, $100 \mu \mathrm{L}$ of the inoculum was added. MIC, defined as the lowest concentration of the test compound which inhibits the visible growth after 18 hrs, was determined visually after incubation for $18 \mathrm{hrs}$ at $37^{\circ} \mathrm{C}$, and the results are presented in Table 2. Tests using DMF as negative control and chloramphenicol (bacteria) or miconazole (fungus) as positive control were carried out in parallel. All tests were performed in duplicate with full agreement between both results.

\section{RESULTS AND DISCUSSION}

\section{Macro- and micromorphology features of the Penicillium sp.}

The conidiophores are biverticillate having smooth to finely rough stipes with 300 to $800 \mu \mathrm{m}$ in length, with inflated apices; conidiophores from the aerial mycelium are shorter. Metulae are formed in verticills of 4-6 on the top of stipes, smooth to finely rough, 9-12 (-15) $\mu \mathrm{m}$ in length, with 
inflated apices (up to $5 \mu \mathrm{m}$ ). Rami are occasionally formed. Phialides are flask-shaped with short necks, 7-10 × 2-3 $\mu \mathrm{m}$, in number of 5 or more per metula. Conidia are green, globose to subglobose, smooth to finely rough, $2-3 \mu \mathrm{m}$, arranged in columns. Structures resembling sclerotia are produced in mycelium. These structures have irregular shape, $50-300 \mu \mathrm{m}$ in size and are formed by a crystalline yellowish green matter mixed with hyphae.

Colonies on CYA ( 7 days, $25^{\circ} \mathrm{C}$ ) were $40-45 \mathrm{~mm}$ in diameter, sulcate, velutinous, mycelium was white to pale at the margins and greyish in the center, sporulation was heavy with greyish green colors, reverse was dark green with cream to yellow margins, clear exudates were produced in variable amounts and a dark yellowish green diffusible pigment was produced. Colonies on MEA (7 days, $25^{\circ} \mathrm{C}$ ) were $33-37 \mathrm{~mm}$ in diameter, plane to sulcate, velutinous, mycelium was white, with heavy sporulation, greyish green in the center and blue-green at the margins, reverse was dark green with cream to yellow margins. Exudates were absent; dark yellowish green diffusible pigment was produced in small amounts. Colonies on G25N (7 days, $25^{\circ} \mathrm{C}$ ) were $8-11 \mathrm{~mm}$ in diameter, sulcate, elevated, velutinous, mycelium was white with sparse light green sporulation, reverse was pale, exudates and diffusible pigments were absent (the latter being produced after two weeks). No growth occurred in CYA at $37^{\circ} \mathrm{C}$.

The regular production of biverticillate penicilli with 4 to 6 terminal metulae, and phialides, which were flask shaped and distinctly shorter than metulae by our Penicillium isolate are indicatives that it belongs to the subgenus Furcatum section Furcatum (Pitt, 2000). The growth rate on G25N in 7 days $(8-11 \mathrm{~mm})$ also gave support for this classification. The isolate showed cultural and micromorphological features which are very similar to those of Penicillium raistrickii (Pitt, 2000) (Figure 1). However, other characteristics were quite distinct from those of $P$. raistrickii, such as the production of conidiophores with smooth stipes (Figure 1), colonies with velutinous texture, the production of a dark yellowish green diffusible pigment in all culture media and the absence of true sclerotia in the mycelium. The isolate also showed some affinities with other species in the subgenus Furcatum such as Penicillium paxillii (e.g. long, smooth stipes and metulae with enlarged apices) and Penicillium herquei (e.g. colony reverses of green colors and production of dark yellowish green diffusible pigment in culture media) (Kornerup and Wansher, 1978; Pitt, 1979) but these affinities were not sufficient for an accurate identification. Therefore, we maintained this fungus identification only at the genus level to avoid misidentifications commonly reported for Penicillium species.

\section{Secondary metabolites isolated}

An aliquot of the bioactive EtOAc extract was loaded on a silica gel chromatography column and eluted using hexane with increasing amounts of EtOAc to afford three new napthalenoids (1-3). Identification of the isolated compounds was carried out by using infrared and modern nuclear magnetic resonance techniques, distortionless enhancement by polarization transfer (DEPT), heteronuclear multiple quantum coherence (HMQC), nuclear overhauser and exchange spectroscopy (NOESY) and heteronuclear multiple bond correlation (HMBC). Compounds were characterized as being methyl 6-acetyl-4methoxy-5,7,8-trihydroxynaphthalene-2-carboxylate (1), methyl 6-acetyl-4-methoxy-7,8-dihydroxynaphthalene-2carboxylate (2) and methyl 6-acetyl-4-methoxy-5,8dihydroxynaphthalene-2-carboxylate (3).

Compound 1, isolated as yellow needles, exhibited, on its infrared spectrum, bands characteristic of hydroxyl (3443 and $\left.1592 \mathrm{~cm}^{-1}\right)$, ketone $\left(1716 \mathrm{~cm}^{-1}\right)$ and aromatic (3398 and $1613 \mathrm{~cm}^{-1}$ ) moieties. The analysis of the ${ }^{1} \mathrm{H}$ and ${ }^{13} \mathrm{C}$ NMR spectra of $\mathbf{1}$ and of DEPT experiment revealed the presence of a methyl group belonging to an acetyl function, two methoxyl groups, two carbonyls, one belonging to an acetate group and the other to an acetyl one, and three hydroxyl groups. The presence of three hydroxyl groups was confirmed by the fact that the acetylation of $\mathbf{1}$ gave triacetate 4 . The placement and the assignments of all the protons and the carbons were supported by the HMBC spectrum. Noticeable were the ${ }^{3} J$ correlations of $\mathrm{H}-3$ and $\mathrm{H}-$ 1 to $\mathrm{C}-10$ and $\mathrm{C}-5$, which allowed us to place $\mathrm{C}-10$ at the ring junction and one hydroxyl group at the $\mathrm{C}-5$ position (Figure 2, Table 1). HMBC correlations of methyl group of the acetyl function group at C-6 to C-7 and C-8 were also observed and confirmed the position of the acetyl and consequently, of the two remaining hydroxyl groups. Full structural data of $\mathbf{1}$ are summarized in Table 1.

Compound 2 was isolated as an amorphous yellow solid and fully identified by the assignments of all the protons and the carbons by comparison with data obtained for compound 1. Structure determination was supported by a combination of $1 \mathrm{D}\left({ }^{1} \mathrm{H}\right.$ and ${ }^{13} \mathrm{C}$ NMR and DEPT) and 2D NMR experiments (NOESY, HMQC and HMBC correlations) data, summarized in Table $1 .{ }^{1} \mathrm{H}$ NMR spectrum showed the presence of an additional aromatic hydrogen signal at $\delta_{\mathrm{H}}$ 6.12, in comparison to 1 , which appeared as a singlet (suggesting, in 2, presence of only two hydroxyl groups). HMQC and DEPT experiments clearly showed signals of three hydrogens bounded to aromatic carbons (C-1, C-3 and C-5). The placement of the additional hydrogen at C-5, rather than at C-7 or C-8, was supported by the NOESY which showed proximity between $\mathrm{H}-5$ and the methoxyl and the acetyl groups respectively in positions 4 and 6 (Figure 2). This assignment was supported by the HMBC correlations of H-5 to C-1 and C-9 (Figure 2).

Compound 3 was obtained in a mixture $(4.8 \mathrm{mg})$ along with compound 2 and its spectral analysis was performed based on the 1D and 2D NMR data obtained for the mixture. A close comparison of compounds $\mathbf{2}$ and $\mathbf{3}$ data led to the attribution of all the signals that are summarized in Table 1. 
Table 2. Minimum inhibitory concentration (MIC) of the selected compounds.

\begin{tabular}{|c|c|c|c|c|c|c|}
\hline \multirow[b]{2}{*}{ Strain } & \multicolumn{6}{|c|}{ MIC $\left(\mu \mathrm{g} \mathrm{mL}^{-1}\right)$} \\
\hline & 1 & 4 & 5 & 6 & $C^{a}$ & $M^{b}$ \\
\hline B. cereus $^{a}$ & $64(64)$ & $128(128)$ & nt & $256(256)$ & $32(32)$ & nt \\
\hline L. monocitogenes ${ }^{a}$ & $64(64)$ & $32(32)$ & $512(512)$ & $256(256)$ & $32(32)$ & nt \\
\hline S. pyogenes ${ }^{a}$ & $128(128)$ & $128(128)$ & $512(512)$ & $512(512)$ & $32(32)$ & nt \\
\hline Listeria $s p^{a}$ & $128(128)$ & $128(128)$ & $256(256)$ & $256(256)$ & $32(32)$ & nt \\
\hline S. typhimurium ${ }^{a}$ & $128(128)$ & $128(128)$ & nt & $256(256)$ & $32(32)$ & nt \\
\hline C. albicans ${ }^{b}$ & $32(32)$ & $64(64)$ & $256(256)$ & $256(256)$ & $\mathrm{nt}$ & $32(32)$ \\
\hline
\end{tabular}

${ }^{\mathrm{a}} \mathrm{C}$ : Chloramphenicol. ${ }^{\mathrm{b}} \mathrm{M}$ : Miconazole. nt: not tested.

Values in parenthesis () refer to the value of the duplicate sample reading.

The general features of the ${ }^{1} \mathrm{H}$ and ${ }^{13} \mathrm{C}$ NMR spectra of compound 3 showed a resemblance to those of compound 2, suggesting it to be a positional isomer of 2 . This observation was consistent with the results obtained from DEPT experiment. The HMBC correlations (H-7 to C-9 and $\mathrm{C}-6)$ permitted to locate the additional aromatic hydrogen at C-7.

Since amounts of compounds $\mathbf{2}$ and $\mathbf{3}$ were not enough to carry on a broad biological screening, three hemi-synthetic derivatives (4-6)of the natural Penicillium metaboliteswere prepared and tested.

All compounds were active on a preliminary disc diffusion assay against the bacteria $L$. monocytogenes, S. pyogenes, Listeria sp., S. typhimurium and B. cereus but, due to availability restrictions, MIC were determined only for compound 1 and derivatives $\mathbf{4 , 5}$ and $\mathbf{6}$. A screening for Candida albicans inhibition was also performed. Derivative 5 was not tested against $S$. typhimurium and $B$. cereus due to small amount available. Results are presented in Table 2.

Naphtalene derivatives are common as constituents of fungi (Frisvad et al. 1998; Vinokurova et al. 2005) andechinoderms (Bandaranayake, 2006). Conventional synthesis of naphtalenoids is a difficult task; therefore, isolation of compound 1 in the present study, with $45.34 \%$ yield from the extract $\left(0.3175 \mathrm{mg} . \mathrm{L}^{-1}\right)$ is very noteworthy making this compound a suitable starting compound for biotechnological use as a new drug lead, since its large scale production is feasible. The isolation of $\mathbf{1}$ in such high yield is also of great importance since this compound can easily be used as a marker for the identification of this Penicillium species. Yield improvement can still take place since modifications in the growing conditions can adequately improve the amount of synthesized secondary metabolites (Wijeratne et al. 2004; Nigam et al. 2007).
Cockrum et al. (1979) used weetbix, yeast extract, sucrose and Difco mycological broth for a comparative study between an Australian and a North American isolate of Penicillium paxilli. The medium used in the present work (glucose, peptone and yeast extract) has some similarities to the medium used by Cockrum et al. (1979). However paxilline, reported as a major metabolite of $P$. paxilli (Munday-Finch et al. 1996) was not detected in the present evaluation.

Narasimhachari and Vining (1963) reported the isolation of two red pigments from $P$. herquei and stated that, according to the growing substrate, this species can produce pigments of a variety of colors such as blue, yellow and green. The same authors described that, in a medium rich in peptone, as the one used for the current work, a deep blue pigment would be formed, fact also not observed in our experiments. Ding et al. (2008) have recently reported the isolation of a urea derivative, hualisyn from $P$. herquei, an aromatic compound that also is not related to the compounds related herein. Nevertheless producing secondary metabolites holding aromatic rings, metabolites previously described for $P$. raistrickii (Belofsky et al. 1998) are also not related to naphalenoids isolated in the present work.

The isolation and identification of compounds 1-3 and the fact that none of those were quoted in other previous studies of the closest species $P$. paxilli, $P$. raistrickii and $P$. herquei could indicate that we may have isolated a species still not described. However, since we obtained only one isolate of this fungus, no more conclusions can be drawn regarding its taxonomic placement. Efforts will be carried out in order to carry on DNA sequencing in order to unambiguously characterize this species. 
In the bioassay, all compounds showed activity against all tested microorganisms, sometimes in concentrations comparable to the controls used, what is not very common since the controls are drugs currently in use, as an accomplishment of many steps of biotechnological improvement of production process. Minimum inhibitory concentration of $\mathbf{1}$ against Candida albicans (MIC 32 $\mu \mathrm{g} / \mathrm{mL}$ ) was the same as the activity showed by miconazole, the positive control. Noticeable were also the activities of 1 against $L$. monocitogenes and $B$. cereus, both assays resulting on a MIC value of $64 \mu \mathrm{g} / \mathrm{mL}$. Acetylation of $\mathbf{1}$ led to a small decrease on its activity but the allylated and metoxylated derivatives (5 and 6) were much less active for all the tested strains. Compound $\mathbf{4}$ exhibited the same activity than positive control chloramphenicol (MIC $32 \mu \mathrm{g} / \mathrm{mL}$ ) against L. monocitogenes, and presented the low MIC value of $64 \mu \mathrm{g} / \mathrm{mL}$ against Candida albicans.

While the acetatylated derivative exhibited good antimicrobial activities, the allyl and methoxy derivatives showed weaker ones, suggesting that the addition of an aliphatic chain lowers the activity. These results are corroborated by the greater bioactivity of $\mathbf{1}$, which possesses three free hydroxyl groups conferring to it a higher polarity.

\section{REFERENCES}

ADRIO, Jose L. and DEMAIN, Arnold L. Fungal biotechnology. International Microbiology, September 2003, vol. 6, no. 3, p. 191-199.

BANDARANAYAKE, Wickramasinghe $\mathrm{M}$. The nature and role of pigments of marine invertebrates. Natural Product Reports, 2006, vol. 23, no. 2, p. 223-255.

BELOFSKY, Gilbert N.; GLOER, Katherine B.; GLOER, James B.; WICKLOW, Donald T. and DOWD, Patrick F. New $p$-terphenyl and polyketide metabolites from the sclerotia of Penicillium raistrickii. Journal of Natural Products, September 1998, vol. 61, no. 9, p. 1115-1119.

COCKRUM, Peter A.; CULVENOR, Culvenor C.; EDGAR, John A. and PAYNE, Alan L. Chemically different tremorgenic mycotoxins in isolates of Penicillium paxilli from Australia and North America. Journal of Natural Products, September 1979, vol. 42, no. 5, p. 534536.

DING, Ling; FOTSO, Serge; LI, Fuchao; QIN, Song and LAATSCH, Hartmut. Hualyzin, a symmetrical urea derivative isolated from Penicillium herquei isolate GA4. Journal of Natural Products, June 2008, vol. 71, no. 6, p. 1068-1069.

FRISVAD, Jens C. and SAMSON, Robert A. Polyphasic taxonomy of Penicillium subgenus Penicillium: A guide to identification of food and air-borne terverticillate Penicillia and their mycotoxins. Studies in Mycology, 2004, vol. 49, p. 1-174.
FRISVAD, Jens C.; BRIDGE, Paul D. and ARORA, Dilip K. Chemical fungal taxonomy. New York; Marcel Dekker, 1998. 398 p. ISBN 0-82470-069-4.

GE, Hui Ming; SHEN, Yao; ZHU, Chun Hua; TAN, Shu Hua; DING, Hui; SONG, Yong Chun and TAN, Ren Xiang. Penicidones A-C, three cytotoxic alkaloidal metabolites of an endophytic Penicillium sp. Phytochemistry, January 2008, vol. 69, no. 2, p. 571-576.

KORNERUP, Andreas and WANSHER, Johan H. Methuen Handbook of Colour. $3^{\text {rd }}$ Ed. London; Eyre Methuen, 1978. $252 \mathrm{p}$.

KWON, Oh Eok; RHO, Mun-Chual; SONG, Hye Young; LEE, Seung Woong; CHUNG, Mi Yeon; LEE, Jeong Hyun; KIM, Young Ho; LEE, Hyun Sun; KIM, YoungKook. Phenylpyropene A and B, new inhibitors of acylCoA: cholesterol acyltransferase produced by Penicillium griseofulvum F1959. Journal of Antibiotics, 2002, vol. 55, no. 11, p. 1004-1008.

LANA, Enio J.L.; CARAZZA, Fernando and TAKAHASHI, Jacqueline A. Antibacterial evaluation of 1,4-benzoquinone derivatives. Journal of Agricultural and Food Chemistry, 2006, vol. 54, no. 6, p. 2053-2056.

LARSEN, Thomas Ostenfeld; LANGE, Lene; SCHNORR, Kirk; STENDER, Steen and FRISVAD, Jens Christian. Solistatinol, a novel phenolic compactin analogue from Penicillium solitum. Tetrahedron Letters, February 2007, vol. 48, no. 7, p. 1261-1264.

LUCAS, Esther M.F.; CASTRO, Mateus C.M. and TAKAHASHI, Jacqueline A. Antimicrobial properties of sclerotiorin, isochromophilone VI and pencolide, metabolites from a Brazilian cerrado isolate of Penicillium sclerotiorum Van Beyma. Brazilian Journal of Microbiology, October-December 2007, vol. 38, no. 4, p. 785-789.

MUNDAY-FINCH, Sarah C.; WILKINS, Alistair L. and MILES, Christopher O. Isolation of paspaline B, an indolediterpenoid from Penicilium paxilli. Phytochemistry, January 1996, vol. 41, no. 1, p. 327-332.

NARASIMHACHARI, N. and VINING, L.C. Studies on the pigments of Penicillium herquei. Canadian Journal of Chemistry, 1963, vol. 41, no. 3, p. 641-648.

NICOLETTI, Rosario; LOPEZ-GRESA, Maria Pilar; MANZO, Emiliano; CARELLA, Angela and CIAVATTA, Maria Letizia. Production and fungitoxic activity of Sch 642305, a secondary metabolite of Penicillium canescens. Mycopathologia, May 2007, vol. 163, no. 5, p. 295-301.

NIGAM, Vinod K.; RUCHI, Verma; KUMAR, Abhisek; KUNDU, Subir and GHOSH, Purnendu. Influence of medium constituents on the biosynthesis of Cephalosporin- 
C. Electronic Journal of Biotechnology, April 2007, vol. 10, no. 2, p. 230-239.

PFENNING, Ludwig H. and ABREU, Lucas M. Diversity of microfungi in tropical soils. In: MOREIRA, F.M.S; SIQUEIRA, J.O. and BRUSSARD, L. eds. Soil Biodiversity in Amazonian and Other Brazilian Ecosystems. Wallingford, Oxfordshire, UK, CABI Publishing, 2006, vol. 1, p. 184-205.

PITT, John I. The genus Penicillium and its teleomorphic states Eupenicillium and Talaromyces. London, Academic Press, 1979. 634 p. ISBN 0125577507.

PITT, John I. A laboratory guide to common penicillium species. $3^{\text {rd }}$ Ed. Australia; Food Science Australia Publishers, 2000. 197 p.

RANCIC, Ana; SOKOVIC, Marina; KARIOTI, Anastasia; VUKOJEVIC, Jelena and SKALTSA, Helen. Isolation and structural elucidation of two secondary metabolites from the filamentous fungus Penicillium ochrochloron with antimicrobial activity. Environmental Toxicology and Pharmacology, July 2006, vol. 22, no. 1, p. 80-84.

REX, John H.; PFALLER, Michael A.; WALSH, Thomas J.; CHATURVERDI, Vishnu; ESPINEL-INGROFF, Ana; GHANNOUM, Mahmoud A.; GOSEY, Linda L.; ODDS, Frank C.; RINALDI, Michael G.; SHEEHAN, Daniel J. and WARNOCK David W. Antifungal susceptibility testing: practical aspects and current challenges. Clinical Microbiology Reviews, October 2001, vol. 14, no. 4, p. 643658.

TAKAHASHI, Jacqueline A. and LUCAS, Esther M.F. Occurrence and structural diversity of fungal metabolites with antibiotic activity. Quimica Nova, 2008, vol. 31, no. 7, p. 1807-1813.

TAKAHASHI, Jacqueline A.; CASTRO, Mateus C.M.; SOUZA, Giovanni G.; LUCAS, Esther M.F.; BRACARENSE, Adriana A.P.; ABREU, Lucas M.; MARRIEL, Ivanildo E.; OLIVEIRA, Mariana S.; FLOREANO, Mônica B. and OLIVEIRA, Thays S. Isolation and screening of fungal species isolated from Brazilian cerrado soil for antibacterial activity against Escherichia coli, Staphylococcus aureus, Salmonella typhimurium, Streptococcus pyogenes and Listeria monocytogenes. Journal de Mycologie Médicale, December 2008, vol. 18, no. 4, p. 198-204.

VINOKUROVA, N.G.; IVANUSHKINA, N.E.; KOCHKINA, G.A.; ARINBASAROV, M.U. and OZERSKAYA, S.M. Production of mycophenolic acid by fungi of the genus Penicillium link. Applied Biochemistry and Microbiology, January 2005, vol. 41, no. 1, p. 83-86.

WIJERATNE, E.M.K.; CARBONEZI, C.A.; TAKAHASHI, J.A.; SELIGA, C.J.; TURBYVILLE, T.J.; PIERSON, E.E.; PIERSON-III, L.S.; WHITESELL, L.;
BOLZANI, V.S. and GUNATILAKA, Leslie. Isolation, optimization of production and structure-activity relationship studies of monocillin I, the cytotoxic constituent of Paraphaeosphaeria quadriseptata. Journal of Antibiotics, 2004, vol. 57, no. 8, p. 541-546. 